\title{
Germinação de sementes de milho com diferentes níveis de vigor em resposta à diferentes temperaturas
}

\section{Germination of corn seeds with different levels of vigor in response to differents temperatures}

\author{
Cesar Augusto Gasparetto Sbrussi ${ }^{1 *}$; Claudemir Zucareli²
}

\begin{abstract}
Resumo
O objetivo do trabalho foi avaliar o desempenho germinativo de sementes de milho, com diferentes níveis de vigor, sob diferentes temperaturas. Utilizaram-se seis lotes de sementes de milho híbrido Balu580 com potenciais germinativos próximos, porém com diferentes níveis de vigor (baixo, intermediário e alto), submetidos a germinação sob temperaturas de $16 ; 19 ; 22 ; 25 ; 28 ; 31 ; 34 ; 37$ e $40^{\circ} \mathrm{C}$ seguindo o delineamento inteiramente casualizado, em esquema fatorial $6 \mathrm{X} 9$, com quatro repetições. Foram avaliadas a porcentagem de plântulas normais na primeira contagem e de plântulas normais, anormais e sementes mortas no teste de germinação. Os dados obtidos foram submetidos à análise de variância, a comparação de médias pelo teste de Tukey $(\mathrm{p}<0,05)$ e, estudo de regressão para efeito de temperaturas. Temperaturas baixas retardam a germinação das sementes, principalmente às de baixo vigor, não sendo observada germinação à $16^{\circ} \mathrm{C}$. Lotes de maior vigor possuem maior desempenho germinativo em todas as temperaturas, porém com destaque em temperaturas supra-ótimas.
\end{abstract}

Palavras-chave: Zea mays, alta temperatura, baixa temperatura, estresse térmico

\begin{abstract}
The objective of this study was to evaluate the performance of maize seeds with different levels of vigor at different germination temperature. To this was used six seed lots of hybrid corn Balu-580 with similar germination potential, but different level of vigor. After the initial characterization of the lots, the effects of temperature were determined by first counting and the germination test conducted on paper substrate germitest, at $16,19,22,25,28,31,34,37$ and $40^{\circ} \mathrm{C}$. The data obtained in the initial characterization of the lots were subjected to analysis of variance and means were compared by Tukey test $(p<0,05)$. In the study of the effect of adverse conditions of temperature on first counting and germination was carried out the analysis of variance following a completely randomized design, factorial scheme $6 \mathrm{X}$ 9. Low temperatures slowed the germination of seeds, especially those of low vigor, and there was no germination at $16^{\circ} \mathrm{C}$. Lots of smaller effect were also more susceptible to high temperatures, with higher percentages of abnormal seedlings and ungerminated seeds.

Key words: Zea mays, high temperature, low temperature, thermal stress
\end{abstract}

\footnotetext{
${ }^{1}$ Eng $^{\circ}$ Agr $^{\circ}$, Discente de Doutorado, Universidade Estadual de Londrina, UEL, Londrina, PR. Bolsista CAPES. E-mail: cesarsbrussi@yahoo.com.br

${ }^{2}$ Eng $^{\circ}$ Agr $^{\circ}$, Prof. Dr. Associado, Dept ${ }^{\circ}$ de Agronomia/Fitotecnia, UEL, Londrina, PR. E-mail: claudemircca@uel.br

* Autor para correspondência
} 


\section{Introdução}

A temperatura é considerada um dos fatores mais importantes na germinação de sementes (NERSON, 2007), devido a sua influencia na absorção de água e outros substratos necessários para o crescimento e desenvolvimento das plântulas. Segundo Marcos Filho (2005) os efeitos da temperatura no processo germinativo de sementes podem ser avaliados a partir de mudanças na porcentagem, velocidade e uniformidade de germinação.

Apesar de ser uma planta de clima tropical e exigir calor e umidade para produzir satisfatoriamente e proporcionar rendimentos compensadores, temperaturas elevadas do solo proporcionam baixa porcentagem de emergência em sementes de milho. $\mathrm{O}$ estresse ocasionado por altas temperaturas ocorre quando, por um período suficiente de tempo, as temperaturas causam danos irreversíveis no desenvolvimento das plântulas (HALL, 2001).

As baixas temperaturas também são consideradas um dos fatores limitantes na produtividade das plantas e, frequentemente causam danos na germinação e no desenvolvimento de plântulas de milho (PARERA; CANTLIFFE, 1994). Guan et al. (2009) relatam que baixas temperaturas induzem danos na membrana celular e afetam as funções fisiológicas das plantas; além de atrasar ou impedir o processo de germinação, deixando as sementes mais suscetíveis a fatores adversos.

A habilidade de uma semente germinar sob amplo limite de condições é definida como a manifestação do seu vigor, dependendo, dentre outros fatores, das condições ambientais encontradas no local quando semeada (SIMONI et al., 2011). A influência do vigor da semente é marcante sobre todos os aspectos do processo germinativo, desde a própria possibilidade de ocorrência da germinação até outras características, como a velocidade, a uniformidade, o total de germinação, o tamanho e a massa das plântulas (CARVALHO; NAKAGAWA, 2000). Nascimento (2000) relata que sementes com alto vigor toleram mais as condições de estresse como altas e baixas temperaturas. Neste sentido, a escolha de sementes com alta qualidade fisiológica e adaptada às condições locais pode ser a razão do sucesso ou insucesso da lavoura (SANS; SANTANA, 2005).

O milho é cultivado em regiões nem sempre favoráveis para a emergência e desenvolvimento inicial das plântulas. Neste contexto, o objetivo do trabalho foi estudar, em condições de laboratório o desempenho germinativo de sementes de milho, com diferentes níveis de vigor sob diferentes temperaturas.

\section{Material e Métodos}

O experimento foi conduzido no Laboratório de Análise de Sementes do Departamento de Agronomia da Universidade Estadual de Londrina (UEL), Londrina-PR. Foram utilizados lotes de sementes de milho do híbrido BALU - 580, tratadas com inseticidas (pirimifós-metílico 50\% 0,016 1/ ton e Deltamethrin 2,5\% 0,04 1/ton) e fungicida (Metalaxyl-M 1,0\% + Fludioxonil 2,5\% 1,00 1/ton) e corante vermelho na concentração $0,201 /$ ton. Para o experimento utilizaram-se seis diferentes lotes de sementes (L1, L2, L3, L4, L5 e L6) com diferentes níveis de vigor, porém com germinação semelhante e dentro dos padrões de comercialização para a espécie.

Foi avaliada a qualidade inicial dos lotes, visando a caracterização e a separação dos mesmos, mediante as seguintes avaliações: Massa de mil sementes: determinada com oito repetições de 100 sementes, conforme descrito nas Regras para Análise de Sementes(BRASIL, 2009). Germinação e Primeira contagem: conduzido com quatro repetições de 100 sementes, em papel toalha umedecido na proporção de 2,5 vezes a massa do substrato. Os rolos de papel, acondicionados em saco plásticos, foram mantidos em germinadores sob temperatura de 25 ${ }^{\circ} \mathrm{C}$. A avaliação constou de duas contagens, aos quatro e sete dias após a instalação do teste. Teste de frio: conduzido utilizando-se a metodologia do 
rolo de papel sem solo, com quatro repetições de 50 sementes (DIAS; BARROS, 1995). Teste de Envelhecimento Acelerado: quatro repetições de 50 sementes envelhecidas a $42{ }^{\circ} \mathrm{C}$ por 72 horas (DIAS; BARROS, 1995) e posteriormente colocadas para germinar segundo as Regras para Análise de Sementes (BRASIL, 2009). Teste de tetrazólio: conduzido empregando-se quatro repetições de 50 sementes conforme metodologia descrita por Dias e Barros (1995). Teste de condutividade elétrica: quatro repetições de 25 sementes, previamente pesadas, foram colocadas para embeber em 75 $\mathrm{ml}$ de água destilada, por um período de 24 horas a $25{ }^{\circ} \mathrm{C}$ (DIAS; BARROS, 1995). Massa seca de plântulas: as plântulas normais obtidas na primeira contagem do teste de germinação foram separadas em duas porções, parte aérea e radicular, e secadas a $60 \pm 5{ }^{\circ} \mathrm{C}$ até massa constante e os resultados foram expressos em grama por plântulas das porções aérea e radicular (NAKAGAWA, 1999). Comprimento de plântulas: Foram distribuídas 10 sementes no terço superior, no sentido longitudinal do papel substrato pré-umedecido. As sementes foram posicionadas com a extremidade da radícula para a parte inferior do papel, sendo, em seguida confeccionados rolos semelhantes ao teste de germinação, com quatro repetições por tratamento e colocados para germinar por quatro dias. Após este período mediu-se em centimetros o comprimento da parte aérea e da raiz primária das plântulas normais. Emergência das plântulas no campo: conduzido com quatro repetições de 50 sementes, semeadas a 5 $\mathrm{cm}$ de profundidade em linhas de $2,5 \mathrm{~m}$, distanciadas de $0,30 \mathrm{~m}$ entre si. A avaliação foi realizada aos 14 dias após a semeadura e o resultado expresso em porcentagem (NAKAGAWA, 1994). Índice de velocidade de emergência das plântulas no campo: conduzido junto com o teste de emergência de plântulas, foram realizadas contagens diárias, a partir da emergência da primeira plântula até o décimo quarto dia. O IVE foi calculado segundo Maguire, citado por Nakagawa (1999).

Após a caracterização inicial dos lotes, foi realizada avaliação da influência das altas e baixas temperaturas sobre a primeira contagem e a germinação. O teste foi conduzido com quatro repetições de 100 sementes, em papel toalha umedecido na proporção de 2,5 vezes a massa (g) do substrato (BRASIL, 2009). Os rolos de papel, acondicionados em sacos plásticos, foram mantidos em germinador tipo câmara, na posição vertical, a $16,19,22,25,28,31,34,37$ e $40^{\circ} \mathrm{C}$. As avaliações foram realizadas, após quatro e sete dias da instalação do teste, computando-se o número de plântulas normais na primeira contagem, bem como o percentual de germinação, de plântulas anormais e de sementes não germinadas ao final do teste.

Para verificar a normalidade e a homogeneidade de variância dos dados, foram aplicados os testes de kolmogovov-Smirnov e Shapiro-Wilk. Os dados obtidos na caracterização dos lotes foram submetidos a análise de variância e as médias comparadas pelo teste de Tukey $(p<0,05)$, seguindo o delineamento inteiramente casualizado.

Nos estudos dos efeitos do estresse térmico e dos níveis de vigor dos lotes sobre a germinação de sementes, foi realizada a análise de variância seguindo o delineamento inteiramente casualizado, em esquema fatorial 6x9. Para os níveis de vigor os dados foram submetidos à comparação de médias pelo teste de Tukey a 5\% e, para efeitos de temperaturas os dados foram submetidos a estudo de regressão até $2^{\circ}$ grau.

\section{Resultados e Discussão}

Quanto à caracterização inicial, todos os lotes de sementes apresentaram porcentagens de germinação acima do padrão utilizado para a comercialização da espécie, $85 \%$ (Tabela 1). A alta porcentagem de germinação é fundamental para o estudo comparativo entre lotes com diferentes níveis de vigor, já que, o processo de deterioração inicia com a redução de vários atributos de desempenho e vigor da semente, resultando, por fim, na perda da capacidade germinativa das sementes (MARTINS; NAKAGAWA; BOVI, 2009). 
Tabela 1. Primeira contagem (P.C), germinação (G), massa seca da raiz (M.S.R), massa seca da parte aérea (M.S.PA), comprimento da raiz (C.A), comprimento da parte aérea (C.PA), Teste de frio (T.F), envelhecimento acelerado (E.A), tetrazólio (TZ), condutividade elétrica (C.E), emergência à campo (E.C) e índice de velocidade de emergência (I.V.E) da caracterização inicial de qualidade fisiológica de seis lotes de milho BALU-580. Londrina, 2011.

\begin{tabular}{|c|c|c|c|c|c|c|}
\hline & P.C & G. & M.S.R & M.S.PA & C.R & C.PA \\
\hline & $(\%)$ & $(\%)$ & (g) & (g) & (cm) & (cm) \\
\hline L1 & $57 \mathrm{~d}$ & 88 & $0,2085 \mathrm{e}$ & $0,6707 \mathrm{~d}$ & $4,5 \mathrm{c}$ & $2,0 \mathrm{c}$ \\
\hline $\mathbf{L} 2$ & $76 \mathrm{c}$ & 88 & $0,3258 \mathrm{~d}$ & $0,3257 \mathrm{c}$ & $6,1 \mathrm{~b}$ & $3,0 \mathrm{~b}$ \\
\hline L3 & $83 \mathrm{~b}$ & 94 & $0,4085 \mathrm{c}$ & $0,3792 \mathrm{c}$ & $6,4 \mathrm{~b}$ & $3,0 \mathrm{~b}$ \\
\hline L4 & $94 \mathrm{a}$ & 95 & $0,5306 \mathrm{~b}$ & $0,5268 \mathrm{~b}$ & $7,7 \mathrm{a}$ & $3,4 \mathrm{ab}$ \\
\hline $\mathbf{L 5}$ & $88 \mathrm{ab}$ & 94 & $0,5231 \mathrm{~b}$ & $0,5635 \mathrm{~b}$ & $7,5 \mathrm{a}$ & $3,6 \mathrm{ab}$ \\
\hline L6 & $94 \mathrm{a}$ & 98 & $0,6958 \mathrm{a}$ & $0,6707 \mathrm{a}$ & $8,2 \mathrm{a}$ & $3,7 \mathrm{a}$ \\
\hline \multirow[t]{2}{*}{$\mathrm{CV}$} & 3,58 & 1,32 & 7,65 & 10,15 & 6,88 & 9,37 \\
\hline & $\begin{array}{l}\text { T.F } \\
\text { (\%) }\end{array}$ & $\begin{array}{l}\text { E.A } \\
(\%)\end{array}$ & $\begin{array}{l}\text { TZ } \\
\text { (\%) }\end{array}$ & $\begin{array}{c}\text { C.E } \\
(\mu \mathrm{S} / \mathrm{cm} / \mathrm{g})\end{array}$ & $\begin{array}{l}\text { E.C } \\
(\%)\end{array}$ & I.V.E \\
\hline L1 & $54 \mathrm{~d}$ & $19 \mathrm{e}$ & $45 \mathrm{c}$ & $19,59 \mathrm{c}$ & $79 \mathrm{~b}$ & $3,19 \mathrm{~d}$ \\
\hline $\mathbf{L} 2$ & $43 \mathrm{e}$ & $48 \mathrm{~d}$ & $70 \mathrm{~b}$ & $19,43 \mathrm{c}$ & $80 \mathrm{~b}$ & $3,51 \mathrm{~cd}$ \\
\hline L3 & $70 \mathrm{c}$ & $61 \mathrm{~cd}$ & $71 \mathrm{~b}$ & $15,17 \mathrm{~b}$ & $89 \mathrm{a}$ & $3,94 \mathrm{bc}$ \\
\hline L4 & $76 \mathrm{bc}$ & $68 \mathrm{bc}$ & $80 \mathrm{ab}$ & $16,45 \mathrm{~b}$ & $92 \mathrm{a}$ & $4,42 \mathrm{a}$ \\
\hline L5 & $83 \mathrm{ab}$ & $79 \mathrm{ab}$ & $71 \mathrm{~b}$ & $16,83 \mathrm{bc}$ & $93 \mathrm{a}$ & $4,34 \mathrm{ab}$ \\
\hline L6 & $91 \mathrm{a}$ & $86 \mathrm{a}$ & $84 \mathrm{a}$ & $12,38 \mathrm{a}$ & $96 \mathrm{a}$ & $4,62 \mathrm{a}$ \\
\hline $\mathrm{CV}$ & 6,28 & 12,8 & 6,72 & 7,41 & 4,15 & 5,13 \\
\hline
\end{tabular}

Fonte: Elaboração dos autores.

Pela análise conjunta dos testes, foi possível a identificação de três diferentes níveis distintos de vigor. O lote L6 e os lotes L1 e L2 mostraram-se significativamente superior (alto vigor) e inferiores (baixo vigor), respectivamente. Os lotes L3, L4 e L5 foram identificados como de vigor intermediário, no entanto, os testes de frio, comprimento de raiz e massa seca da parte aérea e raiz, apontaram a inferioridade do lote L3, comparado aos demais lotes de vigor intermediário.

Freitas et al. (2002) e Mattioni, Albuquerque e Mendonça (2009) também encontraram, em sementes de algodão, diferenças entre os testes utilizados quanto a classificação do vigor dos lotes, sendo que esta diferença pode, segundo Krzyzanowski, Vieira e França-Neto (1999), variar conforme o teste utilizado, dependendo da característica avaliada e do genótipo das sementes.
A porcentagem de germinação diferiu entre os lotes em todos os tratamentos, com exceção à temperatura de $16^{\circ} \mathrm{C}$, onde foi observada ausência de plântulas normais, devido à atraso na germinação dos lotes, não sendo possível avaliar o efeito do vigor das sementes (Tabela 2). As temperaturas de 37 e $40^{\circ} \mathrm{C}$, mostraram-se drásticas para todos os lotes de sementes, acarretando em decréscimos substanciais no potencial germinativo. Apesar da baixa porcentagem de germinação, o lote L6 e os lotes L1 e L2, mostraram-se superior e inferior aos lotes de vigor intermediários, respectivamente. A habilidade de uma semente germinar sob amplo limite de condições é definida como a manifestação do seu vigor, dependendo, entre outros fatores, das condições ambientais encontradas no local onde foi semeada (SIMONI et al., 2011). 
Tabela 2. Porcentagem de germinação, plântulas normais, plântulas anormais e sementes não germinadas de lotes de sementes de milho, híbrido Balu-580, submetidos a diferentes temperaturas. Londrina, 2011.

\begin{tabular}{|c|c|c|c|c|c|c|c|c|c|}
\hline \multicolumn{10}{|c|}{ PORCENTAGEM DE GERMINAÇÃO } \\
\hline LOTES & $16 \mathrm{C}^{\circ}$ & $19 \mathrm{C}^{0}$ & $22 C^{0}$ & $25 \mathrm{C}^{0}$ & $28 C^{0}$ & $31 \mathrm{C}^{\circ}$ & $34 \mathrm{C}^{0}$ & $37 \mathrm{C}^{0}$ & $40 \mathrm{C}^{\circ}$ \\
\hline $\mathbf{L 1}$ & 0 & $20 \mathrm{c}$ & $85 \mathrm{c}$ & $88 \mathrm{~b}$ & $87 \mathrm{cb}$ & $83 \mathrm{c}$ & $81 \mathrm{~b}$ & $9 \mathrm{c}$ & $2 d$ \\
\hline $\mathbf{L 2}$ & 0 & $40 \mathrm{~b}$ & $89 \mathrm{cb}$ & $88 \mathrm{~b}$ & $85 \mathrm{c}$ & $87 \mathrm{cb}$ & $82 \mathrm{~b}$ & $9 \mathrm{c}$ & $11 \mathrm{c}$ \\
\hline $\mathbf{L 3}$ & 0 & $46 \mathrm{~b}$ & $96 \mathrm{ab}$ & $94 \mathrm{ab}$ & $95 \mathrm{a}$ & $93 \mathrm{ab}$ & $92 \mathrm{a}$ & $37 \mathrm{~b}$ & $5 \mathrm{dc}$ \\
\hline L4 & 0 & $81 \mathrm{a}$ & $93 \mathrm{abc}$ & $95 \mathrm{ab}$ & $98 \mathrm{a}$ & $95 \mathrm{a}$ & $93 \mathrm{a}$ & $20 \mathrm{~b}$ & $19 \mathrm{~b}$ \\
\hline L5 & 0 & $75 \mathrm{a}$ & $93 \mathrm{abc}$ & $94 \mathrm{ab}$ & $94 \mathrm{ab}$ & $97 \mathrm{a}$ & $92 \mathrm{a}$ & $21 \mathrm{~b}$ & $24 \mathrm{~b}$ \\
\hline L6 & 0 & $81 \mathrm{a}$ & $98 \mathrm{a}$ & $98 \mathrm{a}$ & $98 \mathrm{a}$ & $94 \mathrm{ab}$ & $96 \mathrm{a}$ & $47 \mathrm{a}$ & $43 \mathrm{a}$ \\
\hline $\mathrm{CV}$ & & & & & $6,35 \%$ & & & & \\
\hline \multicolumn{10}{|c|}{ LÂNTULAS NORMAIS } \\
\hline $\mathbf{L 1}$ & 0 & 0 & $0 \mathrm{~d}$ & $80 \mathrm{~b}$ & $75 \mathrm{~b}$ & $78 \mathrm{c}$ & $69 \mathrm{c}$ & $8 \mathrm{~d}$ & $0 \mathrm{~d}$ \\
\hline L2 & 0 & 0 & $2 \mathrm{~cd}$ & $84 \mathrm{~b}$ & $77 \mathrm{~b}$ & $81 \mathrm{bc}$ & $80 \mathrm{~b}$ & $8 \mathrm{~d}$ & $10 \mathrm{cb}$ \\
\hline L3 & 0 & 0 & $3 \mathrm{bcd}$ & $92 \mathrm{a}$ & $91 \mathrm{a}$ & $89 \mathrm{ab}$ & $90 \mathrm{a}$ & $31 \mathrm{~b}$ & $4 \mathrm{dc}$ \\
\hline L4 & 0 & 0 & $16 \mathrm{a}$ & $95 \mathrm{a}$ & $96 \mathrm{a}$ & $94 \mathrm{a}$ & $92 \mathrm{a}$ & $19 \mathrm{c}$ & $15 \mathrm{~b}$ \\
\hline L5 & 0 & 0 & $11 \mathrm{ab}$ & $94 \mathrm{a}$ & $92 \mathrm{a}$ & $95 \mathrm{a}$ & $90 \mathrm{a}$ & $20 \mathrm{c}$ & $15 \mathrm{~b}$ \\
\hline L6 & 0 & 0 & $10 \mathrm{abc}$ & $98 \mathrm{a}$ & $97 \mathrm{a}$ & $93 \mathrm{a}$ & $93 \mathrm{a}$ & $52 \mathrm{a}$ & $42 \mathrm{a}$ \\
\hline \multirow{2}{*}{\multicolumn{10}{|c|}{$\frac{8,56 \%}{\text { PORCENTAGEM DE PLÂNTULAS ANORMAIS }}$}} \\
\hline & & & & & & & & & \\
\hline L1 & $0 \mathrm{~b}$ & $68 \mathrm{a}$ & $12 \mathrm{a}$ & 8 & 6 & 8 & $8 \mathrm{ab}$ & $67 \mathrm{a}$ & $62 \mathrm{a}$ \\
\hline L2 & $0 \mathrm{~b}$ & $47 \mathrm{~b}$ & $8 \mathrm{ab}$ & 7 & 8 & 7 & $12 \mathrm{a}$ & $68 \mathrm{a}$ & $44 \mathrm{~b}$ \\
\hline $\mathbf{L 3}$ & $0 \mathrm{~b}$ & $49 \mathrm{~b}$ & $3 a b$ & 5 & 1 & 4 & $5 \mathrm{ab}$ & $48 \mathrm{~b}$ & $58 \mathrm{a}$ \\
\hline L4 & $0 \mathrm{~b}$ & $17 \mathrm{c}$ & $3 a b$ & 2 & 0 & 2 & $4 \mathrm{ab}$ & $69 \mathrm{a}$ & $58 \mathrm{a}$ \\
\hline L5 & $25 \mathrm{a}$ & $22 \mathrm{c}$ & $4 \mathrm{ab}$ & 4 & 4 & 2 & $4 \mathrm{ab}$ & $71 \mathrm{a}$ & $60 \mathrm{a}$ \\
\hline L6 & $16 \mathrm{a}$ & $18 \mathrm{c}$ & $1 \mathrm{~b}$ & 1 & 1 & 5 & $2 b$ & $51 \mathrm{~b}$ & $42 \mathrm{~b}$ \\
\hline \multirow{2}{*}{\multicolumn{10}{|c|}{$\frac{22,12 \%}{\text { DE SEMENTES NÃO }}$}} \\
\hline & & & & & & & & & \\
\hline L1 & $100 \mathrm{a}$ & $12 a$ & 3 & 4 & 7 & $9 a$ & $11 \mathrm{a}$ & $24 a$ & $36 \mathrm{~b}$ \\
\hline L2 & $100 \mathrm{a}$ & $13 a$ & 3 & 5 & 7 & $6 \mathrm{ab}$ & $6 \mathrm{ab}$ & $23 \mathrm{ab}$ & $45 \mathrm{a}$ \\
\hline L3 & $100 \mathrm{a}$ & $5 \mathrm{~b}$ & 1 & 1 & 3 & $3 \mathrm{ab}$ & $3 \mathrm{ab}$ & $15 \mathrm{bc}$ & $37 a b$ \\
\hline L4 & $100 \mathrm{a}$ & $2 \mathrm{~b}$ & 4 & 2 & 2 & $3 \mathrm{ab}$ & $3 \mathrm{ab}$ & $11 \mathrm{c}$ & $23 \mathrm{c}$ \\
\hline L5 & $75 \mathrm{~b}$ & $3 \mathrm{~b}$ & 3 & 2 & 2 & $1 \mathrm{ab}$ & $4 \mathrm{ab}$ & $8 \mathrm{~cd}$ & $16 \mathrm{~cd}$ \\
\hline L6 & $14 \mathrm{c}$ & $1 \mathrm{~b}$ & 1 & 1 & 1 & $1 \mathrm{~b}$ & $2 \mathrm{~b}$ & $2 \mathrm{~d}$ & $15 \mathrm{~d}$ \\
\hline $\mathrm{CV}$ & \multicolumn{9}{|c|}{$22,29 \%$} \\
\hline
\end{tabular}

*Médias seguidas por letras iguais na coluna não diferem pelo teste de Tukey aos 5\% de probabilidade.

Fonte: Elaboração dos autores.

Em temperaturas supra-ótimas ocorre maior velocidade do processo germinativo, mas somente as sementes mais vigorosas conseguem germinar, determinando assim, uma redução na porcentagem de germinação (CARVALHO; NAKAGAWA, 2000), justificando os maiores valores do lote L6 mesmo nas temperaturas mais altas.

De acordo com Hampton (2002), apesar de o vigor exercer profunda influência sobre a produção de várias culturas, esses efeitos manifestam-se principalmente devido a possíveis diferenças na porcentagem de germinação e emergência das plântulas. Segundo França-Neto, Krzyzanowski e Henning (2011) o uso de sementes vigorosas assegura o estabelecimento de uma população adequada de plantas, mesmo sob condições estressantes.

Com exceção do lote L3 na temperatura de 
$19^{\circ} \mathrm{C}$, os lotes de vigor intermediários também diferiram estatisticamente dos lotes de baixo vigor, apresentando maiores porcentagens de germinação. Por outro lado, quando comparados ao lote L6, maior vigor, estes obtiveram menores porcentagens de germinação apenas nas temperaturas extremas de 37 e $40^{\circ} \mathrm{C}$ (Tabela 2). Corroborando os resultados, França-Neto, Krzyzanowski e Henning (2010) relatam que em condições de estresse durante a emergência, lavouras originadas de sementes de alta qualidade sofrem consequências menos drásticas, resultando em maiores produtividades em relação às originárias de sementes de médio ou baixo vigor.

Nas temperaturas entre 22 e $34^{\circ} \mathrm{C}$ são observadas altas taxas de germinação em todos os lotes de sementes de milho. No entanto, mesmo nessas temperaturas ainda foi possível identificar diferenças entre os lotes de sementes estudados, sendo observadas menores porcentagens de germinação dos lotes L1 e L2, confirmando à maior sensibilidade e qualidade fisiológica inferior destes lotes mesmo sob temperaturas favoráveis para germinação.

$\mathrm{Na}$ Figura 1 estão apresentados os resultados de germinação dos seis lotes de sementes em resposta as diferentes temperaturas estudadas. O comportamento dos seis lotes de sementes em resposta a temperatura ajustou-se a uma função quadrática, indicando que as baixas e altas temperaturas acarretaram em menores porcentagens de germinação (Figura 1), principalmente dos lotes L1 e L2, ressaltando a inferioridade dos mesmos.

Figura 1. Germinação dos lotes de sementes de milho, híbrido Balu-580, submetidos a diferentes temperaturas.

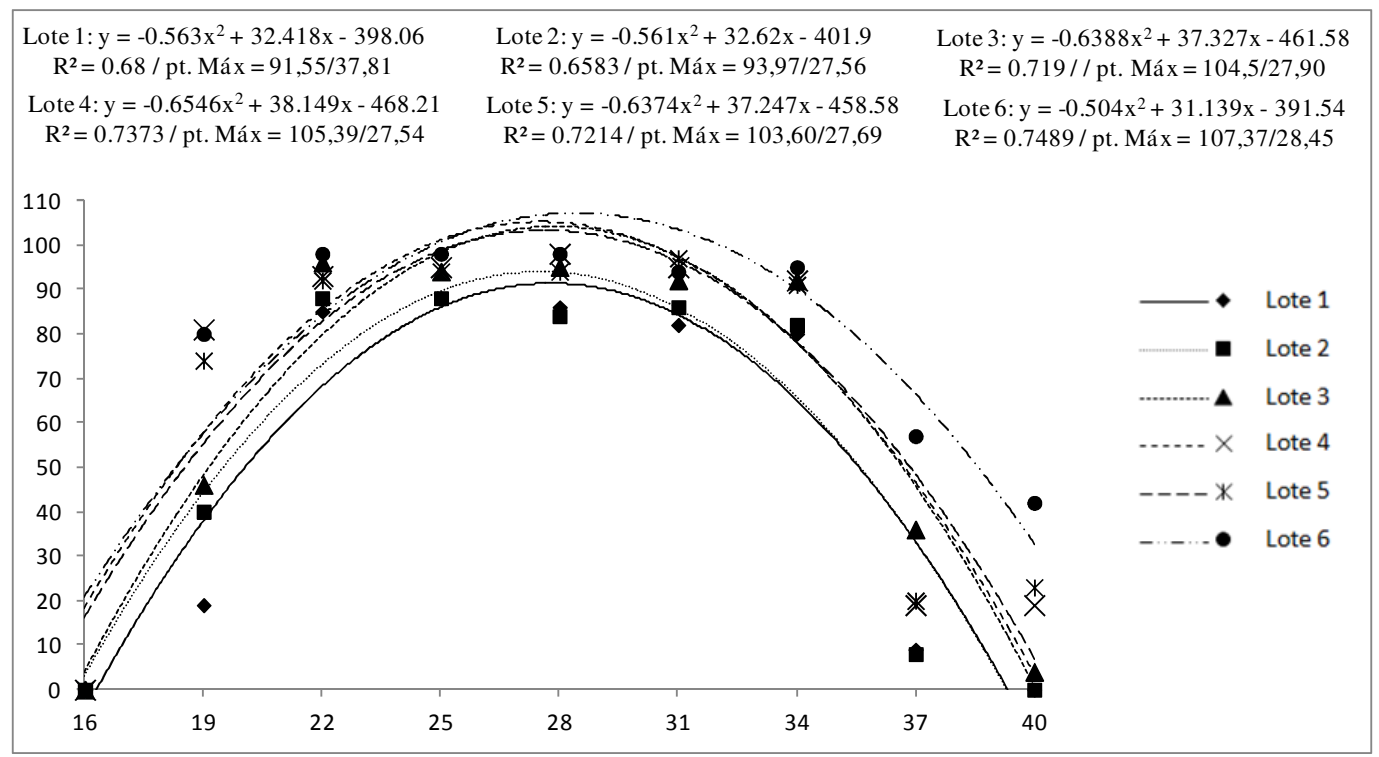

Fonte: Elaboração dos autores.

O percentual de germinação das sementes foi maior entre $22 \mathrm{e} 34^{\circ} \mathrm{C}$, sendo que os pontos de máxima situaram-se entre 28,45 e $27,54^{\circ} \mathrm{C}$, nos lotes L1 e L4 respectivamente. Os resultados obtidos concordam com Farooq et al. (2008), os quais relatam que a temperatura ótima para germinação de sementes de milho encontra-se entre 25 e $28^{\circ} \mathrm{C}$, no entanto, são contrários aos de Marcos Filho (2005), que sugere temperaturas mais elevadas, entre 32 e $35^{\circ} \mathrm{C}$, para obtenção de maiores porcentagens de germinação.

Com o aumento da temperatura, observa-se acréscimo na germinação dos lotes de sementes, até aproximadamente $28{ }^{\circ} \mathrm{C}$, decrescendo a partir dessa temperatura. Nota-se também que a taxa de 
acréscimo e decréscimo na germinação são menos acentuados entre as temperaturas de 22 à $34{ }^{\circ} \mathrm{C}$, respectivamente, apontando que a germinação das sementes torna-se mais estável e homogênea entre estas temperaturas. Segundo Steckel, Sprague e Stoller(2004), isto ocorre, pois nas faixas sub-ótimas e supra-ótimas, a taxa de germinação responde linearmente à temperatura e nas temperaturas ótimas, estas quase não se alteram. Borba et al. (1995), estudando germinação de sementes de diversos genótipos de milho, em diferentes temperaturas, também observaram a partir da temperatura de $35{ }^{\circ} \mathrm{C}$ um declínio acentuado e significativo na porcentagem de germinação.

As temperaturas altas propiciaram maior diferenciação entre os lotes, comparadas com as baixas temperaturas, destacando-se o lote L6, considerado inicialmente como de maior vigor. Segundo Mauri et al. (2010), somente as sementes mais vigorosas conseguem germinar sob temperaturas máximas.

$\mathrm{Na}$ Tabela 2 são apresentados os resultados da porcentagem de plântulas normais da primeira contagem do teste de germinação, os quais, apesar de inferiores, mostraram-se semelhantes aos obtidos na porcentagem de germinação (Tabela 2). Segundo Bhering et al. (2003), a primeira contagem do teste de germinação pode ser utilizada como um teste de vigor, uma vez que à medida que a deterioração da semente avança a velocidade de germinação é reduzida.

As sementes identificadas como de baixo vigor na caracterização inicial dos lotes (L1 e L2), apresentaram, em todas as temperaturas, menores porcentagens de plântulas normais comparadas aos lotes de vigor intermediário (L4 e L5) e de alto vigor (L6). O lote L3, também classificado como de vigor intermediário, foi superior ao lote L1 em todos os tratamentos, no entanto, não apresentou diferença significativa em relação ao lote L2 nas temperaturas de 22 e $40^{\circ} \mathrm{C}$.

Segundo Carvalho e Nakagawa (2000), sementes de alto vigor são potencialmente mais capazes de resistir a estresses ambientais, justificando os resultados apresentados pelo lote L6 nas temperaturas acima e abaixo da ótima para a espécie. França-Neto, Krzyzanowski e Henning (2010) acrescentam que sementes de vigor médio ou baixo resultam em plântulas fracas com pouca ou nenhuma possibilidade de se estabelecerem competitivamente no campo.

A ausência de germinação na primeira contagem estendeu-se à temperatura de $19{ }^{\circ} \mathrm{C}$, enfatizando que as temperaturas baixas acarretam em atraso na germinação, impedindo a avaliação do efeito do vigor nas temperaturas de 16 e $19^{\circ} \mathrm{C}$ (Tabela 2). Segundo Nascimento (2000), o atraso na germinação se deve, principalmente, ao menor ou maior comprimento da Fase II durante o processo de embebição de água pelas sementes, influenciada pelas temperaturas, visto que temperaturas baixas reduzem enquanto as temperaturas altas aumentam a velocidade de germinação. Bewley e Black (1994) acrescentam que baixas temperaturas podem diminuir a capacidade da semente em absorver água, limitando a atividade de várias vias metabólicas, e reduzir a velocidade do processo germinativo, explicando a ausência de germinação em todos os lotes na primeira contagem de germinação para as temperaturas de 16 e $19^{\circ} \mathrm{C}$ e porcentagens de germinação próxima a zero à $22^{\circ} \mathrm{C}$, na primeira contagem do teste de germinação.

$\mathrm{Na}$ primeira contagem (Figura 2), as linhas de tendência seguem os mesmos comportamentos observados para a porcentagem de germinação (Figura 1), no entanto com valores absolutos inferiores, principalmente para os lotes de menor vigor. A proximidade entre as linhas de tendência dos lotes de sementes nas temperaturas baixas (Figura 2) é devido à ausência da germinação nas temperaturas de 16 e $19^{\circ} \mathrm{C}$ (Tabela 2), indicando que sob baixas temperaturas, houve atraso na germinação até mesmo no lote de maior vigor. No entanto, as diferenças entre lotes foram se acentuando com o aumento da temperatura, realçadas pela maior distância entre as linhas de tendência da primeira contagem, comparada às da germinação (Figuras 1 e 2), indicando maior tolerância do lote de maior vigor sob temperaturas altas. 
Figura 2. Plântulas normais na primeira contagem de germinação dos lotes de sementes de milho, híbrido Balu-580, submetidos a diferentes temperaturas.

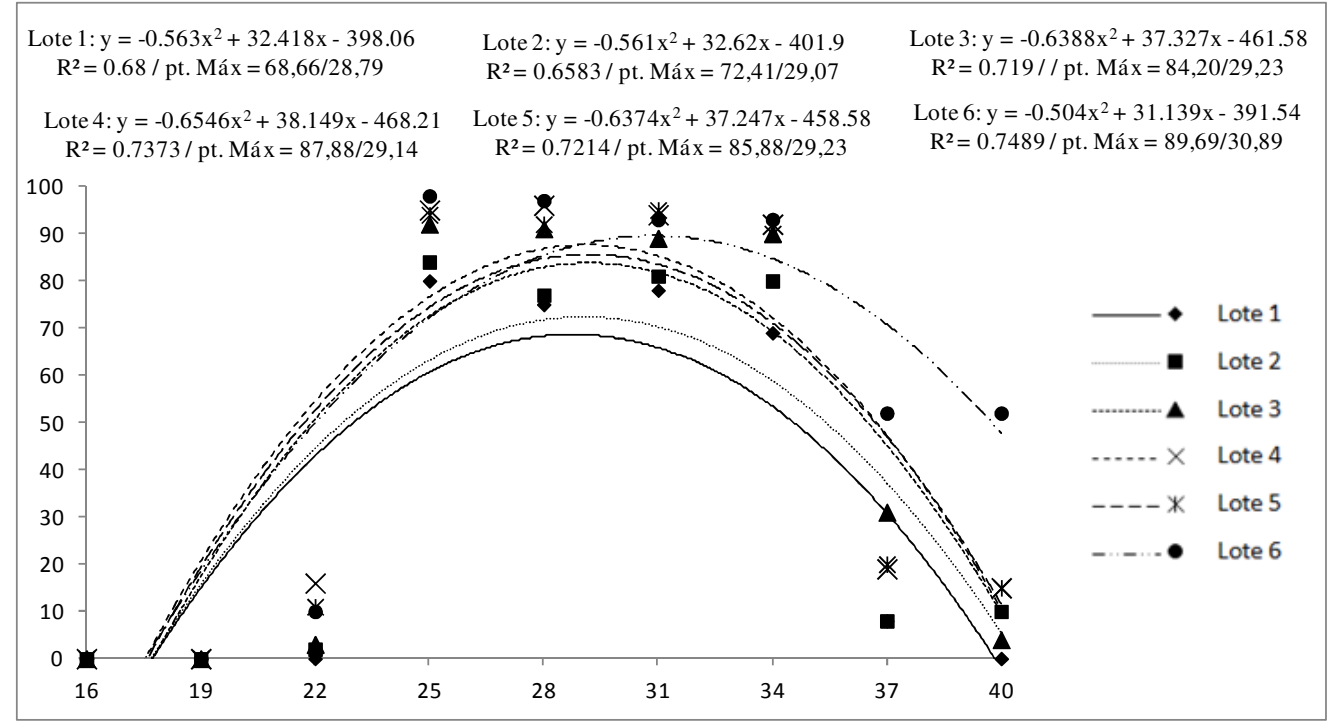

Fonte: Elaboração dos autores.

Com relação aos pontos de máxima resposta, os menores valores, 28,79 e $29,07^{\circ} \mathrm{C}$ foram observados nos lotes L1 e L2, respectivamente, e o maior valor, $30,89^{\circ} \mathrm{C}$, observado no lote de maior vigor, L6. Estes resultados indicam menor tolerância dos lotes de baixo vigor à temperaturas mais altas e maior velocidade de germinação para o lote L6, classificado inicialmente como de maior vigor.

Munizzi et al. (2010), relatam que sementes de maior qualidade fisiológica possuem maior velocidade nos processos metabólicos, propiciando germinações mais rápidas e uniformes de plântulas e segundo Ludwig et al. (2009), a emergência rápida e uniforme das plântulas é de extrema importância para a cultura do milho, justificando o uso de sementes de alta qualidade.

A porcentagem de plântulas anormais diferiu entre os lotes nas temperaturas de 19, 22, 34, 37 e $40^{\circ} \mathrm{C}$, onde o lote L6 apresentou menor número de plântulas anormais (Tabela 2). A ausência de diferença entre lotes nas temperaturas de 25, 28 e $31^{\circ} \mathrm{C}$, deve-se ao fato de que em condições ideais de temperatura a diferença de vigor é amenizada.
Com relação à porcentagem de sementes não germinadas, observou-se comportamento semelhante aos de plântulas anormais (Tabela 2), com ausência de diferença entre os lotes, nas temperaturas de $22,25, \mathrm{e} 28^{\circ} \mathrm{C}$. O lote L6, considerado de alto vigor, superou os demais lotes em todas as temperaturas onde ocorreu diferenças significativas, tanto para porcentagem de plântulas anormais quanto para sementes não germinadas. As sementes dos lotes de alto vigor foram, portanto, menos afetadas em todas as temperaturas, principalmente às menos favoráveis à germinação de sementes de milho (Tabela 2). Estes resultados corroboram com Carvalho e Nakagawa (2000), no qual, relatam que sementes de alto vigor são potencialmente mais capazes de resistirem a estresses ambientais.

Na Figura 2 verifica-se os resultados das plântulas anormais e sementes não germinadas obtidos no teste de germinação em resposta às diferentes temperaturas. A porcentagem de plântulas anormais apresentou decréscimo até aproximadamente 25 ${ }^{\circ} \mathrm{C}$ seguido de acréscimos até a temperatura de 40 ${ }^{\circ} \mathrm{C}$, onde foram observadas as maiores taxas de plântulas anormais em todos os lotes (Figura 3). Sob 
temperaturas mais altas, a velocidade de absorção de água e as atividades enzimáticas tornam-se mais elevadas, fazendo com que as sementes germinem mais rapidamente (VARELA, COSTA; RAMOS, 2005). Entretanto, segundo Dousseau et al. (2008), temperaturas muito elevadas podem ser prejudiciais à germinação de algumas espécies, provavelmente por causarem desnaturação de proteínas essenciais ao processo germinativo.

Figura 3. Plântulas anormais obtidas na germinação de sementes dos lotes de milho, híbrido Balu-580, submetidos a diferentes temperaturas.

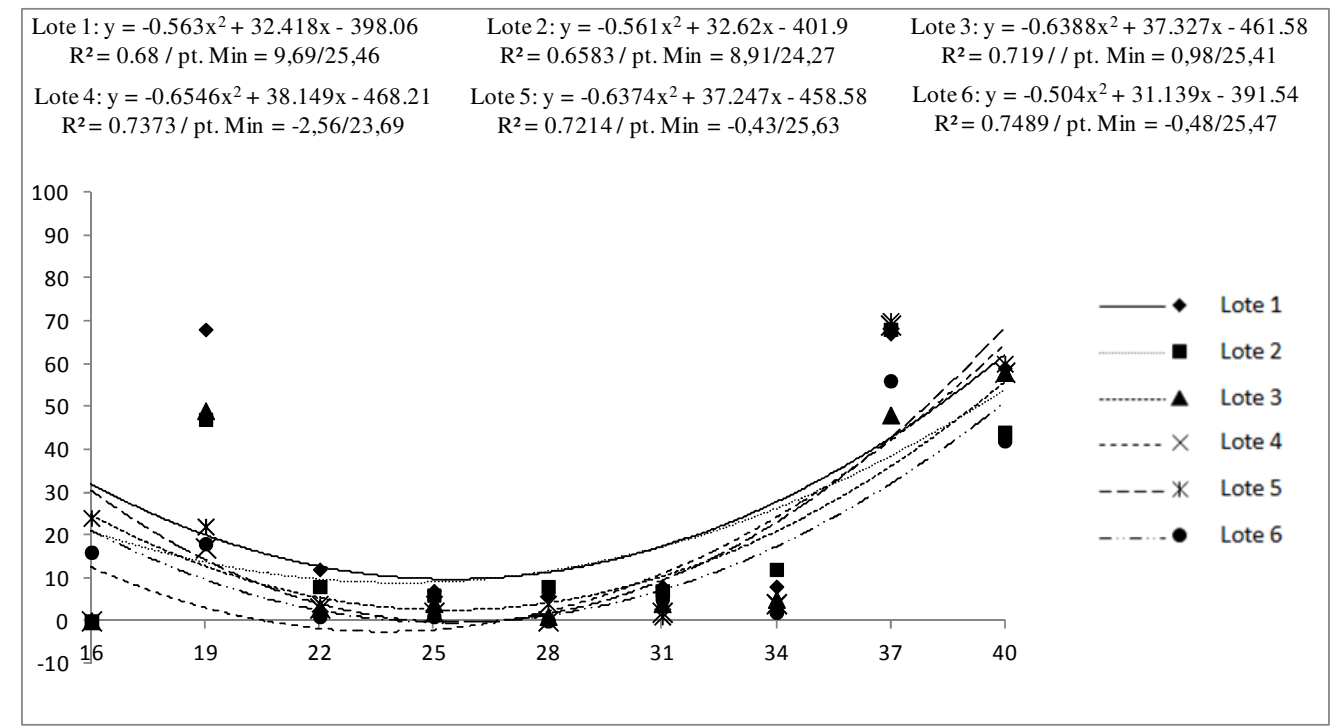

Fonte: Elaboração dos autores.

As maiores taxas de sementes não germinadas foram observadas na temperatura de $16^{\circ} \mathrm{C}$ (Figura 4). Os resultados indicam que, mesmo após sete dias da instalação do teste de germinação, as temperaturas mais baixas $\left(16\right.$ e $\left.19^{\circ} \mathrm{C}\right)$, favoreceram elevadas taxas de sementes não germinadas (Figura 4). Contudo, apesar da ausência de germinação, não é possível afirmar que, as sementes não germinadas estavam mortas, visto que, estas se apresentavam intactas, ou seja, sem liberação de exsudados ou presença de fungos. Segundo Sans e Santa (2005), em condições de baixa temperatura, a emergência das plântulas pode tardar em até quatorze dias. Por outro lado, as altas temperaturas favoreceram um maior número de plântulas anormais, indicando que as sementes submetidas às altas temperaturas deram início ao processo germinativo (Figura 3). Assim, embora tenha estimulado o processo de germinação por meio da protrusão de raiz, as temperaturas de 37 e $40^{\circ} \mathrm{C}$ inibiram o desenvolvimento subsequente do processo germinativo, impedindo, em geral, a formação de plântulas normais no período avaliado. protrusão 
Figura 4. Sementes não germinadas obtidas no teste de germinação de lotes de milho, híbrido Balu-580, submetidos a diferentes temperaturas.

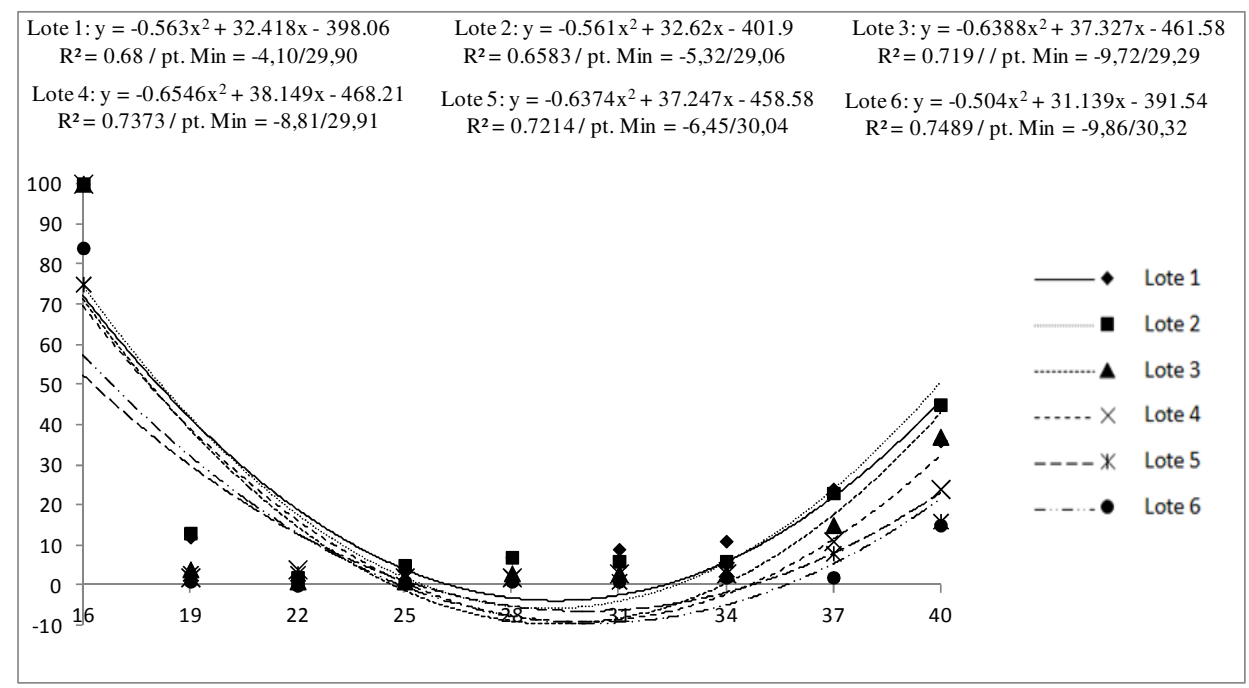

Fonte: Elaboração dos autores.

Estudando a germinação de sementes de diversos genótipos de milho, em diferentes temperaturas, Borba et al. (1995) também observaram, a partir da temperatura de $35^{\circ} \mathrm{C}$, um declínio acentuado e significativo na porcentagem de germinação, sendo que na temperatura máxima de $45^{\circ} \mathrm{C}$, a germinação das sementes não mais ocorreu.

Os resultados obtidos ressaltam a necessidade de gerenciamento das condições de temperatura no momento da instalação da cultura, direcionando os lotes de menor vigor para as regiões ou locais com condições favoráveis e a importância da utilização de sementes de alto vigor, visto que, para todas as variáveis, observou-se a superioridade do lote L6, classificado inicialmente como de maior vigor e a inferioridade dos lotes L1 e L2, caracterizados como de baixo vigor, mesmo quando submetidos a condições de estresse térmico. Além da superioridade das sementes de alto vigor na velocidade e emergência total, conforme constatado neste experimento, segundo Hösf (2003), estas características podem se estender ao tamanho inicial, produção de matéria seca e as taxas de crescimento das plantas.

\section{Conclusão}

Temperaturas baixas retardam a germinação das sementes, principalmente às de baixo vigor, não sendo observada germinação à $16^{\circ} \mathrm{C}$.

Lotes de maior vigor possuem maior desempenho germinativo em todas as temperaturas, porém com destaque em temperaturas supra-ótimas.

\section{Referências}

BEWLEY, J. D.; BLACK, M. Seeds: physiology of development and germination. $2^{\text {nd }}$ ed. New York: Plenum Press, 1994.

BHERING, M. C.; DIAS, D. C. F. S.; BARROS, D. I.; DIAS, L. A. S.; TOKUHISA, D. Avaliação do vigor de sementes de melancia (Citrullus lunatus Schrad.) pelo teste de envelhecimento acelerado. Revista Brasileira de Sementes, Brasília, v. 125, n. 2, p. 1-6, dec. 2003.

BORBA, C. S.; ANDRADE, R. V.; AZEVEDO, J. T.; ANDREOLI, C.; PURCINO, A. A. C. Germinação de sementes de diversos genótipos De milho tropical (zea mays 1.) em diferentes temperaturas. Revista Brasileira de Sementes, Brasília, v. 16, n. 2, p. 141-144, 1995.

BRASIL. Ministério da Agricultura e Reforma Agrária. Regras para análise de sementes. Brasília: SNDA/ DNDV/CLAV, 2009. 364 p. 
CARVAlHO, N. M.; NAKAGAWA, J. Sementes: ciência, tecnologia e produção. Jaboticabal: FUNEP, 2000. 588 p.

DIAS, M. C. L. L.; BARROS, A. S. R. Avaliação da qualidade de sementes de milho. Londrina: IAPAR, $1995.43 \mathrm{p}$.

DOUSSEAU, S.; ALVARENGA, A. A.; ARANTES, L. O.; OLIVEIRA, D. M.; NERY, F. C. Germinação de sementes de tanchagem (Plantago tomentosa Lam.): influência da temperatura, luz e substrato. Ciência e Agrotecnologia, Lavras, v. 32, n. 2, p.4 38-443, mar./abr. 2008.

FRANÇA-NETO, J. B.; KRZYZANOWSKI, F. C.; HENNING, A. A. A importância do uso de sementes de soja de alta qualidade. [S.1: s.n], 2010. (Folder, n. 1).

FRANCA-NETO, J. de B.; KRZYZANOWSKI, F. C.; HENNING, A. A. Sementes de soja de alta qualidade: a base para altas produtividade. In: CONGRESO DE LA SOJA DEL MERCOSUR, 5.; FORO DE LA SOJA ASIA, 5., 2011, Rosário. Anais... Rosario, 2011. p. 1-4. Disponível em: <http:/ainfo.cnptia.embrapa.br/digital/ bitstream/item/47558/1/FRANCA-NETO.sementes. pdf.>. Acesso em: 12 set. 2013.

FREITAS, R. A.; DIAS, D. C. F. S.; CECON, P. R.; REIS, M. S.; DIAS, L. A. S. Storability of cotton seeds predicted by vigour test. Seed Science and Technology, Zürich, v. 30, n. 2, p. 403-410, 2002.

GUAN, Y.; HU, J.; WANG, X.; SHAO, C. Seed priming with chitosan improves maize germination and seedling growth in relation to physiological changes under low temperature stress. Seed Science Center, Crosschecked, v. 10, n. 6, p. 427-433, apr. 2009.

HALL, A. E. Heat Stress and its impact. New York: Crop Response to Environment, CRC Press, 2001.

HAMPTON, J. G. What is seed quality? Seed Science and Technology, Zürich, v. 30, n. 1, p. 1-10, 2002.

HÖSF, A. Emergência e crescimento de plântulas de arroz em resposta a qualidade fisiológica. 2003. Tese (Doutorado em Ciência e Tecnologia de Sementes) Faculdade de Agronomia Eliseu Maciel. Universidade Federal de Pelotas, Pelotas.

KRZYZANOWSKI, F. C; VIEIRA, R. D.; FRANÇANETO, J. (Coord.). Vigor de sementes: conceitos e testes. Londrina: ABRATES, 1999. 218 p.

LUDWIG, M. P.; SCHUCH, L. O. B.; LUCCA FILHO, O. A.; AVELAR, S. A. G.; MIELERZRSKI, F.; OLIVEIRA, S.; CRIZEL, R. L. Desempenho de sementes e plantas de milho híbrido originadas de lotes de sementes com alta e baixa qualidade fisiológica. Revista Brasileira de Milho e Sorgo, Sete Lagoas, v. 8 n. 1, p. 83-92, 2009.

MARCOS FILHO, J. Fisiologia de sementes de plantas cultivadas. Piracicaba: Fealq, 2005. 495 p.

MARTINS, C. C; NAKAGAWA, J.; BOVI, M. L. A. Avaliação da qualidade fisiológica de sementes de açaí. Revista Brasileira de Fruticultura, Jaboticabal, v. 31, n. 1, p. 231-235, 2009.

MATTIONI, F.; ALBUQUERQUE, M. C. F.; MENDONÇA, E. A. F. Desempenho de sementes de algodoeirosubmetidas a diferentes tipos de estresses. Revista Brasileira de Sementes, Londrina, v. 31, n. 1, p. 80-85, 2009.

MAURI, J.; LOPES, J.; FERREIRA, A.; AMARAL, J. T.; FREITA, A. R. Germinação de semente e desenvolvimento inicial da plântula de brócolos em função de substratos e temperaturas Scientia Agrária, Curitiba, v. 11, n. 4, p. 275-280, 2010.

MUNIZZI, A.; BRACCINI, A. L.; RANGEL, M. A. S.; SCAPIM, C. A.; ALBRECHT, L. P. Qualidade de sementes de quatro cultivares de soja, colhidas em dois locais no estado de Mato Grosso do Sul. Revista Brasileira de Sementes, Brasília, v. 32, n. 1, p. 176-185, 2010.

NAKAGAWA, J. Testes de vigor baseados na avaliação das plântulas. In: VIEIRA, R. D.; CARVALHO, N. M. (Ed.). Testes de vigor de sementes. Jaboticabal: FUNEP, 1994. 164 p.

Testes de vigor baseados no desempenho de plântulas. In: KRZYZANOWSKI, F. C.; VIEIRA, R. D.; FRANÇA NETO, J. B. Vigor de sementes: conceitos e testes. Londrina: ABRATES, 1999. p. 2.1-2.24.

NASCIMENTO, W. M. Temperatura X germinação. Seed News, Pelotas, v. 4, n. 4, p. 44-45, jul./ago. 2000.

NERSON, H. Seed production and germinability of cucurbit crops. Seed Science Biotechnology, Israel, v. 1, n. 1, p. 1-10, 2007.

PARERA, C. A.; CANTLIFFE, D. J. Presowing seed priming. Horticultural Reviews, Florida, v. 16, n. 4, p. 109-141. 1994.

SANS, L. M. A.; SANTANA, D. P. Cultivo do milho: clima e solo. Sete Lagoas: EMBRAPA Milho e Sorgo, 2005. (Informações técnicas, 5).

SIMONI, F.; COSTA, R. S.; FOGAÇA, C. A.; GEROLINETO, E. Sementes de Sorghum bicolor L. - 
Gramineae, submetidas ao estresse hídrico simulado com PEG (6000). Revista de Biologia e Ciência da Terra, Paraíba, v. 11, n. 1, p. 188-192, 2011.

STECKEL, E. L.; SPRAGUE, L. C.; STOLLER, W. E. Temperature effects on germination of nine Amaranthus species. Weed Science, Champaign, v. 52, n. 2, p. $217-$ 221, 2004.
VARELA, V. P.; COSTA, S. S.; RAMOS, M. B. P.Influência da temperatura e do substrato na germinação de sementes de itaubarana (Acosmium nitens (Vog.) Yakovlev) - Leguminosae, Caesalpinoideae. Acta Amazônica, Rio Branco, v. 35, n. 1, p. 35-39, 2005. 